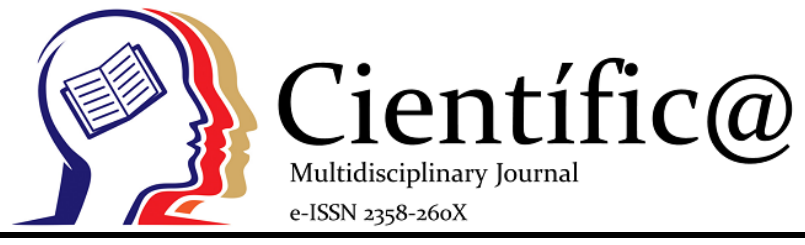

\title{
Aprendizagem Colaborativa E Recursos Educacionais Abertos
}

\author{
Collaborative Learning And Open Educational Resources \\ Antenor Rita Gomes ${ }^{1}$; Paulo Brazão ${ }^{2}$ \\ ${ }^{1}$ Universidade do Estado da Bahia - UNEB - Campus IV - Av. J. J. Seabra, Bairro da Estação . Jacobina, Bahia, Brasil - CEP \\ 4700.000 antenorritagomes@gmail.com \\ ${ }^{2}$ Centro de Investigação em Educação da Universidade da Madeira (CIE-UMa) Colégio dos Jesuítas - Rua dos Ferreiros 9000- \\ 039 Funchal - Portugal jbrazao@staff.uma.pt
}

Info

Recebido: $18 / 02 / 2019$

Publicado: 31/05/2019

DOI: 10.29247/2358-260X.2019v6i1.p16-25

ISSN: 2358-260X

Palavras-Chave

Aprendizagem colaborativa; recursos

sócio tecnológicos; formação de

professores

Keywords:

Collaborative learning; socio-

technological resources; teacher training

\section{Resumo}

O objetivo central deste trabalho é discutir a produção de Recursos Educacionais Abertos (REA) por parte dos educadores, buscando relações com as aprendizagens colaborativas. Dito de outro modo, o trabalho insere-se na reflexão em torno das oportunidades que a produção de artefatos educacionais proporciona para 0 estabelecimento de um cenário educativo colaborativo - 0 texto se pauta em estudos teóricos correlatos e apresenta dados de um projeto de pesquisa em fase de implantação, a ser desenvolvido em rede na Universidade do Estado da Bahia (UNEB - Brasil) e a Universidade da Madeira (UMA Portugal) fruto de uma parceria entre a UNEB a UMA e a Universidade de Cádiz (UCA-Espanha). Nesta ocasião, refletimos sobre as formas de produção e socialização do conhecimento na contemporaneidade, as aprendizagens abertas e compartilhadas e a produção de artefatos sócio tecnológicos para e pela educação.

\footnotetext{
Abstract

The central objective of this work is to discuss the production of Open Educational Resources (OER) by educators, seeking relationships with collaborative learning. In other words, the work is part of the reflection on the opportunities that the production of educational artifacts provides for the establishment of a collaborative educational scenario - The text is based on related theoretical studies and presents data from a research project in phase (UNEB - Brazil) and the University of Madeira (UMa - Portugal), the result of a partnership between UNEB and UMa and the University of Cadiz (UCA - Spain). On this occasion, we reflect on the forms of production and socialization of knowledge in the contemporary world, open and shared learning and the production of socio-technological artifacts for and by education.
} 


\section{CONSIDERAÇÕES INICIAIS}

A sociedade do final do Século XX, início do Século XXI vivencia sensíveis transformações nos modos de produção armazenamento e socialização do conhecimento. Nesse movimento ganham destaque as tecnologias da comunicação e da informação, não só pelo caráter de inovação científica que comportam como também pelos aspectos sócio políticos e educativos que as envolve. As tecnologias contemporâneas ampliaram significativamente as possibilidades de comunicação e, conseqüentemente, o poder simbólico exercido pela comunicação midiática. Estes avanços e a indústria da mídia fazem com que o contorno de algumas instituições culturais como escolas, universidades, igrejas etc. seja, hoje, menos delineado do que o era em meados do Século XX. A distinção mesma entre essas instituições e seus papéis não é tão nítida para a sociedade como fora outrora. Isso tem um desdobramento e um impacto direto na educação.

Por outro lado diversos autores a exemplo de Jesus Martín-Barbero (1999), há muito tem alertado para o fato de que é a experiência do audiovisual que vem integrando as massas à modernidade e não os livros. Isto, se dá em parte, pelo fato de ser o visual um aparato de sentido aberto, plural e híbrido cuja linguagem está para além da noção de código em sentido restrito. $\mathrm{O}$ domínio compreensivo dessa linguagem passa muito mais pelo saber da experiência cultural do que pelo domínio específico de termos. Assim sendo, a produção das visualidades quando situada na experiência das comunidades culturais oportuniza a produção de materiais culturais e educativos que atendem a diversos fins $e$ oportunidades.

O problema que se coloca para a educação, hoje, não é a retenção do movimento evolutivo. Isso seria impossível - embora alguns saudosistas insistam em defender um modelo de escola, pretensamente, imune às transformações sociais como se isso trouxesse de volta uma escola de um tempo imemorial. Tampouco, interessa o desvario da inserção ingênua das novas formas de comunicação e interação como garantia de avanços sócio-educacionais como pensam aqueles que defendem a presença do computador e da internet em sala de aula como se esses recursos por si só tivessem o poder de melhorar a qualidade do ensino e da aprendizagem. Este raciocínio é o mesmo que justifica a simples superação do velho pelo novo. O avanço do conhecimento, verdadeiramente, se dá pela interação entre saberes já existentes e saberes novos. É nesse sentido que deve se dá a superação. No centro da problemática, deve configurar o raciocínio analítico que alimenta a radicalidade da crítica, mas que, a partir das vivências historicamente acumuladas, vislumbra possíveis outros ethos, que serão depois questionados por esse mesmo pensar. A reflexão em torno desta questão não deve poupar esforços, não obstante a diversidade de posições. É um tema que carece, profundamente, ser tencionado pelo pensar crítico e, sobretudo, nos permita compreender os processos, não só como matéria cognitiva, mas, sobretudo como cognição técnica, política e cultural. 
As tecnologias

contemporâneas

possibilitaram o uso da comunicação em escalas cada vez mais abrangentes. Tanto maior a abrangência de um processo comunicacional tanto mais significativo será a seu potencial de interferência nas interações interpessoais porque suas representações atingem um número maior de pessoas (aliás, este é um dos sentidos do termo "comunicação de massa"). A informação semiotizada possibilita a negociação de sentidos e transforma a cultura em produto de consumo. Ela traz consigo UMa mescla dos poderes políticos e econômicos que não só informa, instrui e diverte, e também "educa".

A noção de Educação por sua vez, em termos culturais, pode ser tomada em diversas acepções. Uma delas entende a educação como o trabalho de uma geração sobre a outra com o intuito de lhe transferir conhecimentos, costumes, valores e tradições. Esta função de educar diz respeito a toda sociedade e não somente à instituições específicas, como a escola e a universidade, a quem caberia uma ação especializada desenvolvida por profissionais da área, por meio de ações específicas que envolvem o ensino. As ações educativas não especializadas estão presentes na sociedade em geral, especialmente por meio dos processos de comunicação que, por sua vez, ocupa parte significativa do processo de semiotização e produz peças e artefatos que são por sua vez artefatos sócio culturais e formativos. Qualquer que seja a acepção adotada, a educação irá se processar por meio de ações, e artefatos arquitetados ou não para fins educacativos. De toda sorte, o que se tem são ações educacionais; atos educativos que se pautam em artefatos socioculturais e técnicos.

A ação educativa por meio de artefatos em tempos e termos tecnológicos tem proposições e interações dirigidas, inclusive, para aquela parcela da sociedade ocupada da educação em sentido formal e restrito: a escola e os educadores. $\mathrm{O}$ trabalho do educador e da instituição escolar estão sendo, permanentemente, afetados e questionados quanto a sua função e a sua natureza em decorrência do reordenamento das dimensões espaços-temporais, fato verificável fora e dentro da escola. Desse movimento a produção tecnológica, com suas representações e seu ethos próprio toma parte, tanto em criar e divulgar como em instaurar as novas acepções tidas como verdade, inclusive sobre o próprio ato de educar. Sendo a ação educativa da escola situada em uma sociedade que ao/antes de informar também educa, então, é correto pensar que há uma relação a ser desvelada entre estas duas esferas de conhecimento e poder: os artefatos sociotecnológicos e a Educação.

\section{I - Aprendizagem em contextos de ubiquidade}

U-learning (aprendizagem ubíqua) é o fundamento para possibilidades de aprendizagem que podem ocorrer em qualquer lugar e a qualquer momento. Bruce (2009) considera que a u-learning é muito mais do que um método e sim uma ideia em que as aprendizagens ocorrem não somente em sala de aula mas sobretudo, fora dela como em parques, museus, livrarias, internet etc. para esta acepção de aprendizagem a rede mundial de 
computadores é a perfeita metáfora da ubiquidade posto que as informações ali depositadas estão em todos os lugares, acessíveis de qualquer parte do mundo, Bruce ainda destaca que, ao identificarmos as novas tecnologias como úteis, certamente será mais fácil promover a u-learning (Gomes, Lima e Nunes, 2015).

Neste contexto a noção de aprendizagem passa a ter outra acepção diferente das percepções mais tradicionais que tomam o professor como agente do processo, a escola como centro e o aluno como mero receptor. $\mathrm{O}$ advento das tecnologias traz ao cenário educacional uma noção de aprendizagem que promove deslocamentos de espaço tempo e descentramentos culturais. Este mesmo aparato tecnológico oportuniza acesso ao conhecimento de qualquer lugar e em diferentes tempos sem a hierarquização formal promovida pela escola. Nisto reside certo grau de ubiquidade, abertura e universalização dos saberes inerentes aos modos de aprendizagem contemporânea, que impulsiona a formação dos professores a ser reinventada, à medida que, coloca o educador numa condição de artífice dos processos de construção de conhecimento nos quais o aluno atua como protagonista. Mais do que isso, a formação dos professores, neste caso, precisa ser uma ação contínua e dada pela natureza da sua própria atuação que funciona como um espaço de reflexão constante, incluindo as retomadas e ressignificações necessárias.

Elencamos a seguir, 3 questões que fundamentam esta visão e nos permite pensar mais detalhadamente nessa perspectiva de abertura da escola no contato com os artefactos sócio tecnológicos.

1- Aprender é da ordem do humano; é cultural - O que nos caracteriza como seres humanos e nos diferencia dos outros animais é a cultura. A cultura está em constate transformação e não é a mesma em diferentes pontos do universo habitado, portanto, somos culturalmente construídos e desconstruídos diuturnamente. Aprender é de certa forma, inserir-se nesse movimento de transformação constante. Quanto mais colaborativo é um processo de aprendizagem mais dinâmico é o sistema em que o comporta. Além disso, as aprendizagens são internas e não controladas pela exterioridade fazendo com que diversos fatores de ordem subjetiva interfiram nos processos. Mais que isso, é um movimento também de paradigmas posto que o que é considerado saber em um tempo e lugar ponde não o ser em outro.

2- Aprender é um processo complexo - A noção de complexidade se opõe aos binarismos, aos diretivismos e entende os processos complexos como híbridos, com várias dimensões. O que é tecido junto, multifacetado. Assim, as aprendizagens entendidas como processos complexos são por natureza plurais, hibridizadas e se 
aproximam da noção de movimento e caos.

3- A docência está a serviço das aprendizagens - A docência tem uma dimensão técnica e uma dimensão humana (social, política e cultural) por isto é uma ação complexa. $\mathrm{O}$ resultado do trabalho docente provem de muitas variáveis. Do ponto de vista técnico consiste em organizar: a) situações de ensino - quando a centralidade da ação foca no docente e b) situações de aprendizagem - quando a centralidade do processo está no protagonismo estudantil em contato com o contexto. Em ambos os casos a atuação do professor deve estar a serviço das aprendizagens. Nos casos em que o docente projeta a atuação deliberada do aprendiz como protagonismo a docência consiste em atuar como "diretor de cena" onde o protagonismo é do sujeito que aprende. O planejamento de situações de aprendizagem é como criar "armadilhas" cognitivas para que o aluno aprenda.

\section{II- O Protagonismo e a colaboração nos processos de aprendizagem}

Num sistema de aprendizagem colaborativo todos precisam ser protagonistas. Desse modo, tanto o protagonismo como a colaboração são princípios formativos fundantes o que nos levará necessariamente a uma compreensão da aprendizagem como processo aberto, interativo.
Pensar colaborativamente é o mesmo que pensar em relação sistêmica com o outro, ao modo de uma ecologia cognitiva feita de agenciamentos e relações constitutivas que definem e redefinem possibilidades cognitivas individuais, institucionais e técnicas (Levy, Gatarry). Num sistema cognitivo ecológico todos são coautores.

O protagonismo por definição quer dizer lutador, competidor, batalhador, $\mathrm{Na}$ origem latina (protos) quer dizer principal, primeiro. O termo foi adotado pelo cinema, teatro e televisão para identificar o ator/atriz principal na trama. No sentido cotidiano, usamos o termo para nos referir à pessoa que desempenha o papel principal num acontecimento. Em termos educacionais quer se referir ao aprendiz como agente central do processo,

É fato que as tecnologias digitais da informação e da comunicação provocaram um enorme avanço na promoção da autonomia do estudante e, consequentemente, possibilitam maior protagonismo. Isto se revela em vários aspectos, por exemplo:

a) No acesso, busca e seleção dos conteúdos;

b) No autogerenciamento do tempo e das aprendizagens;

c) No alargamento das fronteiras espaciais e temporais;

d) $\mathrm{Na}$ Universalização e contextualização da informação

e) Na promoção da autoria;

f) Na divulgação e circulação da produção autoral;

g) No retorno e interlocução que possibilita a revisão. 
Logo, uma visão formativa o protagonismo educacional pressupõe movimento /ação/ trabalho. Esta noção é incompatível com as perspectivas de aprendizagem como processo passivo e altera os papeis de aluno e de professor e mudando o foco das situações de ensino para as situações de aprendizagem. Importante ressaltar, também que o protagonismo só acontece com a participação de outrem. Onde há protagonistas, há coadjuvantes. Além disso, existem diferentes níveis e sentidos para o termo. Sendo social, o protagonismo pressupõe a participação e o envolvimento de uma dada comunidade.

Para Carlos Fino (UMA - PT) o protagonismo estudantil é um fundamento mesmo da Inovação pedagógica. Com base nas ideias de Piaget, Vygotsky e Papert; Fino defende a inovação pedagógica como sendo o aluno o protagonista dos processos de aprendizagem e o professor o ator coadjuvante. Devendo o aluno, elaborar ele próprio as estratégias para conhecer e para conhecer suas percepções e habilidades. Telma Weisz, refletindo sobre estes papeis de aluno e professor nos processos de ensinar e aprender, já afirmou que nos processos de ensino e aprendizagem o aluno é como um ator protagonista e o professor o diretor da cena.

Neste caso, enquanto Fino nos faz pensar sobre a necessidade do professor aprender junto com o aluno, Telma Weisz, nos lembra a importância de o professor ter a medida e a direção dos processos, para que o educando não fique abandonado à própria sorte.

\section{III- Os sistemas abertos de produção e os} artefatos educacionais.

Sistemas abertos de produção de conhecimento são lugares de co-produções, por isso, a constituição do próprio sistema deve ser aberta. Embora os projetos caminhem para um resultado que apresenta unicidade, o seu fluxo não deve ser fechado, por essa razão. Como afirma Pretto (2012) constituindo um círculo virtuoso de produção de cultura e conhecimento.

$\mathrm{Na}$ perspectiva dos sistemas abertos algus constructos ou artefatos são também abertos. São os chamados REA (Recursos Educacionais Abertos) Há na literatura contemporânea algumas deficnições básicas para este tipo de artefacto.

Na Declaração de Páris (2012) temos:

"REA são materiais de ensino, aprendizagem e investigação em quaisquer suportes, digitais ou outros, que se situem no domínio público ou que tenham sido divulgados sob licença aberta que permite acesso, uso, adaptação e redistribuição gratuitos por terceiros, mediante nenhuma restrição ou poucas restrições. O licenciamento aberto é construído no âmbito da estrutura existente dos direitos de propriedade intelectual, tais como se encontram definidos por convenções internacionais pertinentes, e respeita a autoria da obra (DECLARAÇÃO DE PARIS SOBRE RECURSOS 


\section{EDUCACIONAIS}

2012).

Em 2011 a Unesco no documento Commonwealth of Learning assim denominou:

"Recursos Educacionais Abertos são materiais de ensino, aprendizado e pesquisa em qualquer suporte ou mídia, que estão sob domínio público, ou estão licenciados de maneira aberta, permitindo que sejam utilizados ou adaptados por terceiros. O uso de formatos técnicos abertos facilita o acesso e o reuso potencial dos recursos publicados digitalmente. Recursos Educacionais Abertos podem incluir cursos completos, partes de cursos, módulos, livros didáticos, artigos de pesquisa, vídeos, testes, software, e qualquer outra ferramenta, material ou técnica que possa apoiar o acesso ao conhecimento.” (Unesco, 2011)

O termo artefato por sua vez sugere engenho produzido para um determinado fim. No caso dos artefatos culturais estes fornecem informações sobre a cultura dos seus criadores e utilizadores, podendo apresentar modificações ao longo do período de tempo em que são valorizados pela cultura. Com a popularização da tecnologia os artefactos tecnológicos complexificaram-se ganhando novas formas de criação, divulgação e uso. Tornou-se quase impossível dissociar as componentes tecnológicas dos elementos sociais que as compõem. Por esse motivo consideramolos elementos sociotecnológicos, resultantes da junção da componente social / cultural que a sua elaboração pressupõe e a natureza tecnológica. Encontramos algumas evidências muito populares de artefactos sociotecnológicos como as páginas das redes sociais, os weblogs, as plataformas customizadas, entre outros tantos. (Brazão e Gomes, 2017)

\section{IV - Uma proposta de pesquisa em aprendizagem colaborativa.}

O projeto

“APRENDIZAGEM COLABORATIVA E PROCESSOS DE FORMAÇÃO: Experiências formativas na produção de artefatos educacionais sociotecnológicos", construído colaborativamente com os pesquisadores da Universidade do Estado da Bahia (UNEB), Universidade da Madeira (UMA) Universidade de Cádiz (UCA), e Universidade Federal do Estado do Rio de Janeiro (UNIRIO) e coordenado pelos professores Dr. Paulo Brazão (UMA) e Antenor Rita Gomes (UNEB) é uma proposta que busca compreender como ocorrem as experiências formativas por meio da Produção de Artefatos Educacionais Sociotecnológicos (AEST) em uma comunidade de prática onde se incluem professores em situação de Formação. Para o desenvolvimento da pesquisa de Inspiração etnográfica será desenvolvida uma plataforma digital interativa envolvendo dois polos de ação e formação (em Jacobina, Bahia, BR e em Funchal, Madeira, PT) por meio da qual serão 
desenvolvidos os processos de formação, autoformação, produção, e socialização dos artefatos produzidos pela pesquisa. A experiência empírica englobará uma fase de autoformação e desenvolvimento de conceitos cujos sujeitos são os membros das equipes pesquisadoras, sob consultoria dos Pesquisadores Carlos Fino (Universidade da Madeira - UMA) Victor Manuel Amar Rodriguez (Universidade de Cádiz_UCA) e Roberto Sídney Alves Macedo (Universidade Federal da Bahia - UFBA) e uma fase de desenvolvimento e experimentação de artefatos educacionais sociotecnológicos que tomarão parte do cenário educativo desenhado pela Plataforma de ação. A segunda fase da pesquisa será desenvolvida por meio de um curso de formação para profissionais da educação e professores dos dois polos e terá duração inicial de 01 ano no qual se espera que cada participante da formação projete cenários educativos constituídos de artefatos educacionais sociotecnológicos. Estes Cenários, seus artefatos e os respetivos processos de construção serão objetos de análise durante toda a pesquisa.

Este Projeto que visa compreender a dimensão formativa dos processos colaborativos de produção de artefatos sociotécnicos por parte dos educadores agindo em comunidades de prática procura atender à seguinte questão: Em que aspectos a produção colaborativa de artefatos educacionais sociotecnológicos se traduz em experiências formativas para os educadores? Assim sendo, a proposta tem por objetivo, compreender como a produção de artefatos educacionais sociotecnológicos em comunidade possibilita e favorece as aprendizagens e contribui com a formação de educadores.

Mais especificamente, objetiva-se:

- Definir o conceito de artefato educacional sociotecnológico no contexto das aprendizagens por participação;

- Compreender a relação entre a produção de artefatos educacionais sociotecnológicos e os contextos culturais dos participantes;

- Identificar aprendizagens por participação desencadeadas durante a produção de artefatos educacionais sociotecnológicos.

- Relatar experiências de aprendizagem ocorridas no processo de construção dos artefatos educacionais sociotecnológicos.

- Perspetivar a dimensão formativa desta ação no contexto da (auto)formação de professores.

Como produto desta pesquisa espera-se produzir:

- Uma coletânea de artigos dos pesquisadores e professores sujeitos da pesquisa;

- Um mega cenário educativo que funcione como repositório de pequenos e médios cenários em que figurem os artefatos sociotécnicos produzidos ao longo da pesquisa e que sejam postados na rede mundial de computadores no formato REA

Espera-se com isso, contribuir com a formação de professores e favorecer as práticas educativas contextualizadas com os tema contemporâneos e de interesse dos educadores. 
Por fim, entendemos que observar a produção dos artefactos sociotecnológicos enquanto elementos transitórios de produção de conhecimento permite-nos entender os mecanismos contextuais da aprendizagem por participação (Brazão e Gomes (2017).

\section{Considerações finais}

Ao por fim a esta breve apresentação de temática tão vasta, podemos sistematizar nossa compreensão a respeito do tema, apontando para 03 dimensões que podem sistematizar as aprendizagens colaborativas pela pespectiva da produção de objetos educacionais.

1 - A Dimensão processual e transformacional. Nesta categoria os artefatos podem ser entendidos enquanto objetos em transição, num processo de transformação que culmina num produto real e pelo movimento que imprime pode alterar e redimensionar a formação dos sujeitos.

2 - A Dimensão formativa e mobilizadora da aprendizagem . Nesta categoria podemos olhar para os artefatos como resultados, como produtos do processo de aprendizagem que irão derivar noutras possibilidades de aprendizagem cada vez mais coletiva e partilhada num desenvolvimento crescente pelo partilhamento.

2 - Dimensão de recurso aberto. Nesta categoria podemos olhar para os artefatos como recurso educacional partilhável (Pretto, 2012 ), em que a noção de autoria é redimensionada.

Nesta perspectiva cremos que novas formas de produção, armazenamento e circulação da informação possa se dar em consonância com novos modos de aprender.

\section{REFERÊNCIAS}

Bruce, Bertram C. (2009). Ubiquitious learning, ubiquitious computing, and lived expirience. In: Cope, B.; Kalantzis, M. Ubiquitous learning. Chicago: University of Illinois Press.

Brazão, Paulo. e Gomes, Antenor ( 2017) PRENDIZAGEM COLABORATIVA E PROCESSOS DE FORMAÇÃO: Experiências formativas na produção de artefatos educacionais sociotecnológico" Universidade do Estado da Bahia. Sistema Integrado de Planejamento - SIP. www.sip.uneb.br

Gomes, Antenor. Lima, Josiane e Nunes, Rodrigo (2015) Multiculturalismo e U-Learning: Novas perspectivas para uma escola Aberta. Rio de Janeiro. Revista Linguistica. Universidade Federal do Rio de Janeiro. P.246-258

Jésus, Martin-Barbero (1999). Novos Regimes de visualidade e descentralizações culturais. In: BRASIL. Ministério da Educação. Mediatamente! Televisão, cultura e educação. Brasília: SEED. p. 17-40. 
Paris, (2012) DECLARAÇÃO DE PARIS SOBRE RECURSOS EDUCACIONAIS ABERTOS, Disponível em http://www.rea.net.br/site/nelson-pretto/ acesso em 03/01/2017

Pretto, Nelson (2012) Recursos Educacionais Abertos: práticas colaborativas e políticas públicas.

http://www.rea.net.br/site/nelson-pretto/ acesso em 03/01/2017

UNESCO (2011), Commonwealth of Learning. ttp://www.rea.net.br/site/comunidade-reabrasil/ acesso em 30/01/2017 